\title{
Preparation of oxichlorate of potash
}

\section{Serullas}

To cite this article: M. Serullas (1831) Preparation of oxichlorate of potash, Philosophical Magazine Series 2, 10:60, 467-467, DOI: 10.1080/14786443108674308

To link to this article: http://dx.doi.org/10.1080/14786443108674308

曲 Published online: 14 Jul 2009.

Submit your article to this journal $2 \pi$

III Article views: 3

Q View related articles $₫$ 
in the fluid from which it was separated by boiling, and the solution has acquired its original properties. The dry mudarine is readily soluble in rectified spirit, and is not precipitated from the alcoholic solution by the addition of water. As long as any considerable portion of spirit remains, it is not coagulated by increase of temperature; but on allowing the spirit to evaporate by exposure to the air, it remains dissolved in water, and has re-acquired its original properties.

It would therefore seem that its tardy solubility, after being contracted, is owing to the state of increased aggregation; for when this is removed by alcohol, its solubility is quickly restored. Mudarine is also extracted by the action of cold water from the powder, but it is not so easily separated from a gummy matter also dissolved, as from the resin extracted along with it by rectified spirit. Its presence is, however, sufficiently demonstrated by the cold infusion gradually losing its transparency as its temperature is increased, and in this case it regains its former transparency, even after having been subjected for some time to the boiling temperature.

We therefore see, that, in this instance a very active principle is more readily dissolved by cold than by boiling water; and it is probable that there are other instances in which heat is improperly employed, with the view of extracting the active principles of vegetable substances,

PREPARATION OF OXICHLORATE OF POTASH. BY M. SERULLAS.

When chlorate of potash is heated in a glass tube or a porcelain crucible, it fuses, boils, and yields oxygen gas. When the fire is properly managed, and after ebullition has taken place for a certain period, the mass thickens, and a moment arrives at which no more oxygen is given out without increasing the heat: if the operation be then stopped, and the salt dissolved and filtered, a great quantity of oxichlorate of potash is' obtained in small brilliant crystals ; 40 parts of chlorate yielded in this way 17.5 of oxichlorate. It appears from the experiments of $M$. Serullas, that chlorate of potash requires a temperature higher than that of boiling mercury for its decomposition, and the oxichlorate a temperature considerably greater.

The moment at which chlorate of potash is converted in to oxichlorate, is ascertained by occasionally putting a spatula into the salt, and withdrawing a small portion of it. This is to be powdered, and treated with a little muriatic acid; if it gives a yellow colour, then some chlorate still remains unconverted.-Ann. de Chim. et de Fhys. Mars 1831.

SEPARATION OF ANTIMONY AND TIN.

M. Gay-Lussac employs tin as a precipitant of the antimony, when the mixed metals have been dissolved in muriatic acid, with a small quantity of nitric acid; muriatic acid being in excess, the antimony is deposited as a black powder, when the tin is immersed in the solution. It requires the application of a moderate heat to produce the separation perfectly; the antimony is to be washed, and dried on the water bath. If the two metals are in solution, and their weight is 